\title{
Providing Infectious Disease Information to Child-Rearing Families and Its Evaluation
}

\author{
Michiko Nohora1, Junko Kurita², Tamie Sugawara ${ }^{3 *}$, Yasushi Ohkusa ${ }^{3}$ \\ ${ }^{1}$ Tokyo Kasei University, Tokyo, Japan \\ ${ }^{2}$ The Graduate School of Health Sciences, Ibaraki Prefectural University of Health Sciences, Ibaraki, Japan \\ ${ }^{3}$ National Institute of Infectious Diseases, Tokyo, Japan \\ Email: *nohara-m@tokyo-kasei.ac.jp
}

How to cite this paper: Nohora, M., Kurita, J., Sugawara, T. and Ohkusa, Y. (2019) Providing Infectious Disease Information to Child-Rearing Families and Its Evaluation. Health, 11, 1135-1146.

https://doi.org/10.4236/health.2019.119087

Received: August 23, 2019

Accepted: September 15, 2019

Published: September 18, 2019

Copyright $\odot 2019$ by author(s) and Scientific Research Publishing Inc. This work is licensed under the Creative Commons Attribution International License (CC BY 4.0).

http://creativecommons.org/licenses/by/4.0/

\begin{abstract}
Background: Earlier study without actual trial indicated that caregivers needed delivery of information about outbreak situations independently of their job status. This report describes, for about two months in winter, actual delivery outbreak information to families with preschool children. The study objective was to confirm the usefulness of this information delivery. Method: Participants receiving outbreak information were recruited from the Child Care Support Service in a ward in Tokyo, Japan. Outbreak information was obtained from the Nursery School Absenteeism Surveillance System (NSASSy) covering approximately $40 \%$ of all nursery schools in Japan, prescription surveillance and other resources. Delivery of outbreak information started in December 2017 and ceased at the end of February in 2018. After the delivery period, a questionnaire survey was administered to participants. Results: For this area, NSASSy showed the most dominant disease was influenza, with 707 patients, followed by group A streptococcal pharyngitis with 98 patients. The outbreak peak was inferred to be as Monday, 22 January, and it was announced by e-mail on 23 January. Of the 202 persons joined this trial, 60 participants responded to the questionnaire survey after the delivery period. Of those respondents, $98 \%$ wanted delivery of that information to continue. Conclusion: We found that almost all respondents confirmed usefulness of the information about infectious diseases which was delivered.
\end{abstract}

\section{Keywords}

Caregivers, Child Care Support, Infectious Diseases, Outbreak Situation, Prevention

\section{Introduction}

Infants are physically and immunologically vulnerable to infection by disease. 
They are frequently infected in family situations and in groups at nursery schools. Moreover, they sometimes have complications associated with infection. However, the most frequent point of anxiety related to childcare, as reported by caregivers, is response to a sudden onset of infectious disease in children [1]. Caregivers employed outside the home must arrange their working schedules and family nursing when children show illness. Demonstrably, caregivers increasingly need information about outbreaks.

Moreover, children in nursery schools or schools are infected easily because of their group life situation. Outbreaks of infectious diseases might propagate at such facilities [2] [3] [4] [5] [6]. They have therefore adopted some measures against infectious diseases and use the Nursery School Absenteeism Surveillance System (NSASSy) to support detection of outbreak situations in the community through surveillance [2] [4] [5]. However, because caregivers cannot access this system directly, caregivers of preschool children who do not attend nursery school or kindergarten cannot receive any information from NSASSy.

The NSASSy uses Japan's unique nursery school culture. Caregivers of children who are absent from nursery schools usually report their symptoms and diseases to their nursery school if a doctor has diagnosed the child. Therefore, surveillance can be accomplished based on symptoms and diagnoses of diseases using information from caregivers. As of the end of 2018, almost 10,000 nursery schools nationwide account for approximately $40 \%$ of all nursery schools in Japan.

An earlier study without actual trial [7] showed that caregivers need delivery of information about outbreak situations independent of their job status. Some needs were confirmed in that earlier study. Nevertheless, as the study presented a hypothetical system: not an actual one. Because the beneficial information depends heavily on its volume, timing and frequency, actual delivery of such information is necessary for evaluation of the delivery information. Therefore, the present study actually provided information of outbreak situation to families with preschool children independently of whether they attend nursery school or kindergarten, or not; then the study evaluated its usefulness. If its benefits were to be confirmed, then the system operation could be extended to other areas. Meeting this objective of the present study requires collaboration with the Child Care Support Service in a ward in Tokyo, Japan.

The Child Care Support Service was established in 1994 by Ministry of Labour (at that time) in Japan to combine working and child care or nursing care of women. Since 2015, it was a Community Child Rearing Support project available to all caregivers with children, irrespective of their working status. Half of them are provided by local governments. The other half are operated by commissioned contractors from local governments, often in cooperation with non-profit organizations. The organization matches users who require child care support and providers who can support child care. The Child Care Support Service takes care of children before opening and after closing of nursery schools, leaving children off and taking charge of them at a nursery school, and taking care of 
children when nursery schools are closed or when caregivers need a break from their responsibilities. The service had been established in 833 municipalities throughout Japan as of the end of 2017; those account for about $45 \%$ of all municipalities in Japan [8]. As of March 2016, 0.6 million users and providers existed in Child Care Support Service nationwide. The share was about $12 \%$, assuming each user has one preschool child. Particularly, in this ward of Tokyo, it covered about $24 \%$ of preschool children residing under the same assumption.

Child Care Support Service includes many users whose preschool children attend nursery school, kindergarten, and even those whose children do not attend either one. In other words, it includes not only working caregivers but also non-working caregivers. One might access caregivers of preschool children who attend nursery school or kindergarten, but access to caregiver of preschool children who attend neither is apparently very difficult. Collaboration with the Child Care Support Service enables us to access caregivers of preschool children irrespective of where the preschool children attend or not. Therefore, we can evaluate this trial while minimizing bias from sampling by collaboration. It is perhaps the largest database of preschool children irrespective of their caregivers' working status other than that of the local government of the ward.

\section{Method}

Participants receiving outbreak information were recruited from users and providers belonging to Child Care Support Service in ward A, Tokyo. Request documents were sent to them enclosed in mail messages from the Child Care Support Service. They can participate in receiving outbreak information by sending e-mail to a certain e-mail address. Recruit mail messages were sent to 383 providers and 3101 users of the Child Care Support Service. In all, 202 persons joined the program. Therefore, the participant rate was $6 \%$ to join the program. However, proportion of providers or users was unknown.

Delivery of the outbreak information had started on 26 December 2017 and ceased on 27 February in 2018. During that period, outbreak information was sent once a week by e-mail.

The e-mail messages included information about the outbreak of infectious diseases, precautionary measures, and reminders. Outbreak information consisted of the daily situation in NSASSy in ward A, the class closure situation provided by the educational board [9], prescription surveillance [10] [11] [12], and other public information related to Tokyo and other areas in Japan.

After the delivery period, a questionnaire survey was administered to participants, both users and providers, with no personal information through web. In the survey, participants were asked about volume, timing and frequency of delivered information and its usefulness for precautionary measures. Though the asked items for provider were the same as the items for users, we focused on the answer from users only so as to consider its usefulness for supporting child-rearing families. The survey site on the web was closed at the end of March, 2018. 
The outbreak situation in the delivery period was assessed by the total number of patients by infectious diseases among nursery school children from NSASSy in ward A. For influenza, the epidemic curve was also shown by subtype of influenza virus in nursery school children from NSASSy in ward A by the epidemiological week for the same duration. The information in the survey was summarized as the number of respondents and its distribution.

\section{Ethics}

This study was approved by the Ethical Committee of Tokyo Women's Medical University on 24 November 2017, with approval number 4561.

\section{Results}

Information was delivered ten times by e-mail at 10 o'clock every Tuesday. Table 1 shows dominant infectious diseases reported for nursery school children in ward A by NSASSy during the delivery period. The most dominant disease was influenza, with 707 patients, followed by group A streptococcal pharyngitis, with 98 patients, and gastroenteritis infection (GI) with 28 patients. Figure 1 depicts

Table 1. Number of absences in nursery school caused by infectious disease during the delivery period in ward A from 26 December 2017 to 27 February 2018.

\begin{tabular}{cc}
\hline Diseases & Number of Absences from Nursery Schools \\
\hline Influenza & 707 \\
A-SP & 98 \\
GI & 28 \\
HFMD & 26 \\
PCF & 9 \\
EI & 9 \\
ES & 8 \\
Varicella & 7 \\
RS & 4 \\
Mumps & 3 \\
Head louse & 3 \\
Herpangina & 2 \\
Impetigo & 2 \\
EKC & 2 \\
Kawasaki disease & 2 \\
Mycoplasma infection & 1 \\
ather adenirus infection & 2 \\
\hline
\end{tabular}

Note: HFMD, hand, foot and mouth disease; GI, gastroenteritis infection; RS, respiratory syncytial virus infection; PCF, pharyngoconjunctival fever; A-SP, group A streptococcal pharyngitis; EI, erythema infectiosum; ES, exanthem subitum; EKC, epidemic keratoconjunctivitis. Subjects were nursery school children in ward A, Tokyo, Japan. Period was December 2017 through February 2018. Data source: Nursery School Absenteeism Surveillance System. 


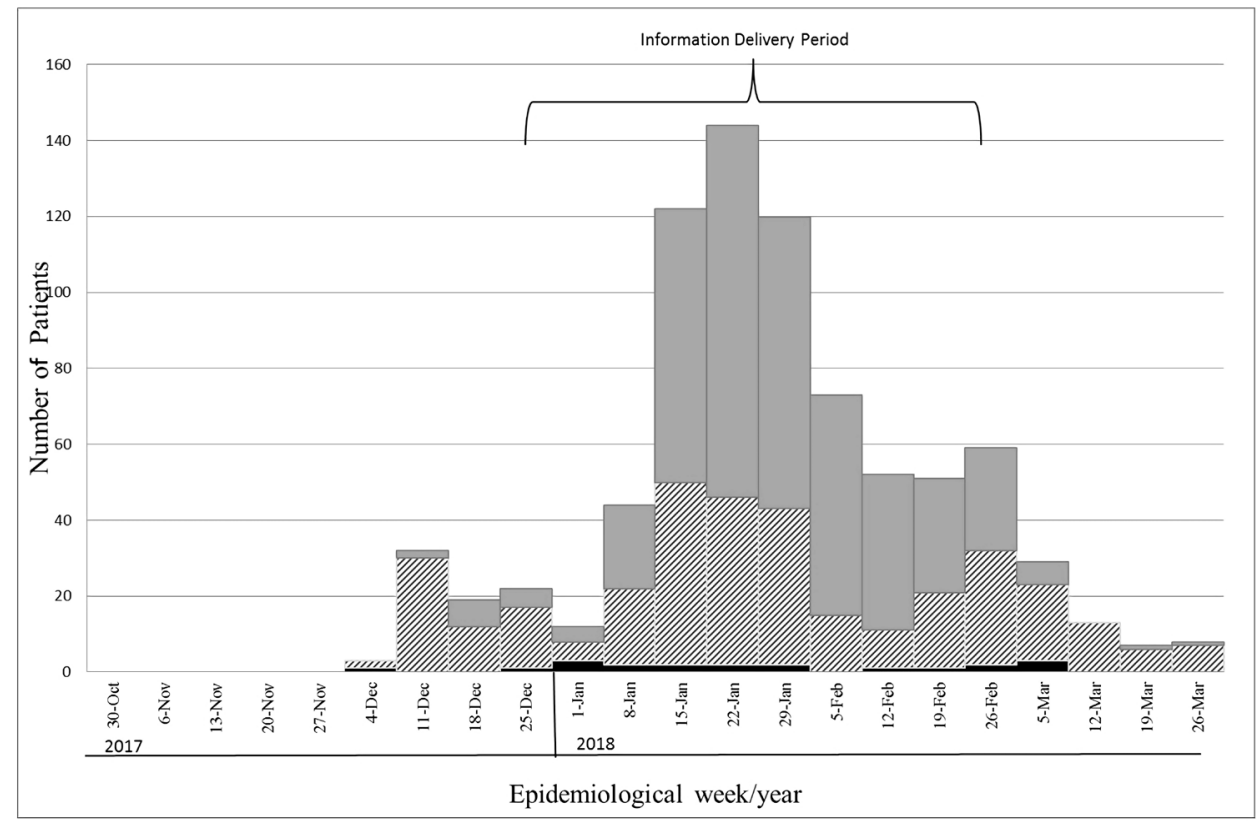

Figure 1. Number of absences from nursery school with influenza by subtype by epidemiological week in ward A, Tokyo, Japan. Note: Gray bars represent the number of patients with influenza A, bars with slash indicate influenza B. Black bars represent influenza patients of a subtype that was not reported or unclassified. Epidemiological week is defined from Monday through Sunday. The horizontal axis shows the date on Monday. Subjects were nursery school children in ward A, Tokyo, Japan. The period was 30 October 2017 to 2nd April 2018, even though the information delivery period was from 26 December 2017 to 27 February 2018. Data source: Nursery School Absenteeism Surveillance System.

the epidemic curve of influenza by subtype by week. The outbreak peak was presumed to be 22 January. It was announced it by e-mail on 23 January. On 30 January, the peak was confirmed because the number of patients declined from the prior week, and was announced.

Of 202 participants, 60 persons responded to the questionnaire survey after the delivery period. Therefore, the response rate was about $30 \%$. Among them, 12 respondents were provider and 48 respondents were user. Table 2 presents the survey results from 48 users. Most respondents were women in their 30 s or 40 s. Actually, $40 \%$ of respondents also registered with the sick child custody service. Most children attend nursery schools or kodomoen, which is hybrid nursery school and kindergarten. Results show that $12 \%$ of children attended no facility. Almost all children attend (nursery) schools in the same ward. Actually, $70 \%$ of children received influenza vaccinations that season; $60 \%$ of them received one every year. Fewer than $20 \%$ of caregivers used the Child Care Support Service. Responses show that $75 \%$ caregivers were concerned about the outbreak situation in facilities their child attended; $81 \%$ of them received some information of outbreak situation from the facilities. In addition, $20 \%$ children felt illness during the survey period: the major symptoms were fever and respiratory symptoms. During the survey period, the influenza incidence was $20 \%$; one child was hospitalized. 
Table 2. Summary of survey results.

\begin{tabular}{|c|c|c|c|c|c|c|c|}
\hline & & $\begin{array}{l}\text { Number of } \\
\text { Respondents }\end{array}$ & $\%$ & & & $\begin{array}{l}\text { Number of } \\
\text { Respondents }\end{array}$ & $\%$ \\
\hline \multirow[t]{4}{*}{ Age class } & $20 \mathrm{~s}$ & 2 & 4.2 & $\begin{array}{l}\text { Did you use Child Care } \\
\text { Support Services during } \\
\text { the delivery period? }\end{array}$ & Yes & 8 & 16.7 \\
\hline & $30 \mathrm{~s}$ & 25 & 52.1 & & No & 40 & 83.3 \\
\hline & $40 \mathrm{~s}$ & 20 & 41.7 & $\begin{array}{c}\text { Are you concerned } \\
\text { about outbreaks in facilities } \\
\text { your children attend? }\end{array}$ & Yes & 36 & 75.0 \\
\hline & $50 \mathrm{~s}$ & 1 & 2.1 & & No & 7 & 14.6 \\
\hline \multirow[t]{2}{*}{ Sex } & Male & 2 & 4.2 & & Attend no facility & 5 & 10.4 \\
\hline & Female & 46 & 95.8 & $\begin{array}{l}\text { Receiving information } \\
\text { of outbreak situation } \\
\text { from the facilities. }\end{array}$ & Yes & 39 & 81.3 \\
\hline $\begin{array}{l}\text { Are you registered } \\
\text { with a sick child }\end{array}$ & Yes & 20 & 41.7 & & No & 4 & 8.3 \\
\hline custody service? & No & 28 & 58.3 & & Attend no facility & 5 & 10.4 \\
\hline Children go to & Nursery school & 26 & 54.2 & Illness in the delivery period & Yes & 10 & 20.8 \\
\hline \multirow[t]{5}{*}{ (Multiple responses) } & Komodoen & 9 & 18.8 & & No & 38 & 79.2 \\
\hline & Kindergarten & 3 & 6.3 & Symptoms of illness & Fever & 9 & 18.8 \\
\hline & Elementary School & 8 & 16.7 & (Multiple responses) & Rash & 3 & 6.3 \\
\hline & Other & 2 & 4.2 & & Vomiting & 1 & 2.1 \\
\hline & Attend no facility & 6 & 12.5 & & Diarrhea & 2 & 4.2 \\
\hline \multirow[t]{5}{*}{ Facilities children attend } & In the same ward & 41 & 85.4 & & $\begin{array}{l}\text { Respiratory } \\
\text { symptoms }\end{array}$ & 8 & 16.7 \\
\hline & $\begin{array}{c}\text { Outside the living } \\
\text { ward }\end{array}$ & 1 & 2.1 & $\begin{array}{l}\text { Hospitalization } \\
\text { among illness children }\end{array}$ & Yes & 1 & 2.1 \\
\hline & Attend no facility & 6 & 12.5 & & No & 9 & 18.8 \\
\hline & Yes & 34 & 70.8 & Influenza onset & Yes & 10 & 20.8 \\
\hline & No & $\underline{14}$ & $\underline{29.2}$ & & No & 38 & 79.2 \\
\hline \multirow[t]{3}{*}{ Influenza vaccination } & Every year & 30 & 62.5 & $\begin{array}{l}\text { Hospitalization among } \\
\text { influenza infected children }\end{array}$ & Yes & 1 & 2.1 \\
\hline & Sometimes & 3 & 6.3 & & No & 9 & 18.8 \\
\hline & Never & 15 & 31.3 & & & & \\
\hline
\end{tabular}

Note: Of 202 participants, 60 responded to the questionnaire survey. Among them, 12 respondents were provider and 48 respondents were user. Table presents the survey results from users only so as to consider its usefulness for supporting child-rearing families. Kodomoen is a hybrid nursery school and kindergarten. The survey site was opened on 27 February, 2018 and closed on the end of March, 2018. "Symptoms of illness" showed symptoms of illness of 10 users whose children had Illness in the delivery period. "Hospitalization among influenza infected children" indicates the number of hospitalization among 10 users whose children were infected influenza.

Table 3 presents respondents' evaluations about providing information related to infectious diseases, which is the objective of the present study. Of respondents, $97.9 \%$ reported it as useful. Only one respondent reported that it was not useful, but this person was unable to receive e-mail message with infectious diseases information other than surveys. Therefore, all respondents who received 
Table 3. Opinion for providing information about infectious diseases.

\begin{tabular}{|c|c|c|c|}
\hline & & Number of Respondents & $\%$ \\
\hline Is the infectious & Yes & 47 & 97.9 \\
\hline disease information useful? & No & 1 & 2.1 \\
\hline \multirow[t]{3}{*}{ Volume } & Too much & 0 & 0.0 \\
\hline & Neither & 44 & 91.7 \\
\hline & Less & 4 & 8.3 \\
\hline \multirow[t]{3}{*}{ Timing } & Appropriate & 35 & 72.9 \\
\hline & Neither & 13 & 27.1 \\
\hline & Inappropriate & 0 & 0.0 \\
\hline \multirow[t]{3}{*}{ Frequency } & More & 13 & 27.1 \\
\hline & Appropriate & 35 & 72.9 \\
\hline & Less & 0 & 0.0 \\
\hline Which information was useful? & Outbreak situation & 48 & 100.0 \\
\hline \multirow[t]{2}{*}{ (Multiple answer) } & Disease information measure & 15 & 31.3 \\
\hline & Precaution measure & 17 & 35.4 \\
\hline \multirow[t]{3}{*}{$\begin{array}{l}\text { Do you want to continue } \\
\text { receiving the information? }\end{array}$} & Yes & 47 & 97.9 \\
\hline & No & 0 & 0.0 \\
\hline & Neither & 1 & 2.1 \\
\hline Did you report the received & Yes & 38 & 79.2 \\
\hline information to families or others? & No & 10 & 20.8 \\
\hline
\end{tabular}

Note: of 202 participants, 60 responded to the questionnaire survey. Among them, 12 respondents were provider and 48 respondents were user. Table presents the survey results from users only so as to consider its usefulness for supporting child-rearing families. The survey site was opened on 27 February, 2018 and closed on the end of March, 2018.

infectious disease information responded that it was useful. Of the respondents, $92 \%$ and $73 \%$ were gratified, respectively, with its volume and timing. It is noteworthy that only $73 \%$ of respondents were gratified with its frequency, implying that the other $27 \%$ respondents wanted the reporting to be more frequent.

Regarding its delivered contents, all respondents reported that knowing the outbreak situation was beneficial. Additionally, $31 \%$ of respondents reported that disease information was beneficial; $35 \%$ of respondents reported that information for precautionary measures was beneficial. Regarding information sharing, $79 \%$ of respondents spoke about the delivered information with their families or others. Finally, $98 \%$ of respondents wanted to continue to receive that information.

\section{Discussion}

As described previously, the peak of influenza outbreak was presumed to be as 22 January, Monday on 23 January. That presumption was confirmed on 30 
January. Therefore, the participants knew, nearly in real time, the peak of outbreak on 23 January.

In stark contrast, for non-participants, similar information was available as published by National Official Sentinel Surveillance for Infectious Diseases, which is operated by the Ministry of Health, Labour and Welfare and based on the Infectious Control Law [13]. That information which was confirmed and published through mass media that the peak nationwide was the week of 29 January to 4 February on 14 February when the reported number of patients was confirmed to have declined from the prior week. Therefore, peak information was provided to participants was provided about three weeks in advance of information provided to non-participants.

Usually, the number of absences and patients associated with infectious diseases was much higher on Monday than on other days because hospitals and clinics are closed on weekends [12]. Patients who had experienced onset on Saturday visited a doctor on Monday as along with patients who had onset on Sunday. Therefore, assessing the dynamic of patients day-by-day is worthwhile. Results show that real-time monitoring is a necessity.

Two sources of real-time monitoring were available in Japan: NSASSy and prescription surveillance (PS) [14] [15] [16] [17], covering approximately 9950 pharmacies, accounting for about 19.6\% of all pharmacies, as of December 2014. The benefit of NSASSy and PS were confirmed in earlier studies [2] [3] [4] [5] [6] [11] [12] [13], but its cost-effectiveness remained uninvestigated. One exceptional study of NSASSy, as yet unpublished, demonstrated that it can reduce the disease burden of common pediatric infectious diseases by, at most, 181.83 208.24 billion yen. Benefit-cost ratio was estimated at approximately $70-80$ : it is much more cost-effectiveness than routine immunization for children. For example, for hepatics B, it was 2.43 [18], and for varicella, it was 2.73 [19]. Although no report of the relevant literature describes a study of the cost-effectiveness of PS, its cost-effectiveness might be readily apparent. As described above, it collects medical claim information through ASP. Therefore, PS burdens nobody with external cost in any way. The result shows that PS is cost-effective, but its net benefit remains unclear.

Onset in children is usually sudden. Therefore, arrangements at a caregiver's workplace are expected to be difficult. Sometimes, caregivers might not take leave if they cannot arrange such a time with employers. In such cases, children cannot be absent from (nursery) school. For that reason, they cannot visit a doctor. Under such circumstances, if caregivers report the possibility of absence because of the child's sudden onset to their workplace, then arrangements related to the working schedule might be made. If so, when a child has a sudden onset, the ill child can be absent from (nursery) school and visit a doctor, thereby improving the quality of life of the child considerably. Three weeks of advance notice might allow some arrangement at a caregiver's workplace.

For the first time, this study provided outbreak information to families with children directly. Results show that almost all of them want to continue to re- 
ceive such information. As one might expect, a higher need for that information was confirmed. Because the delivery period was winter, influenza was the caregivers' greatest concern. However, hand, foot and mouth disease (HFMD) or herpangina, which might break out in summer, respiratory syncytial virus infection, which sometimes occurs as a complication affecting infants, or GI, which was the third dominant disease, all of which might occur in a larger outbreak, might be a concern of caregivers of preschool children along with influenza. Therefore information delivery year-round can be expected to support families using child care. Examination of that benefit remains a challenge for future study.

The survey administered after the delivery period revealed that this group had health concerns because children's influenza vaccination rate was higher than $70 \%$. Furthermore, more than $70 \%$ of them expressed concern about facilities for children attended. More than $80 \%$ of them had received some information about infectious diseases from facilities. Even among this group concern about health, $20 \%$ of children felt illness and had been infected with influenza in one hospitalized case. Among those with high health concerns and larger outbreaks of influenza, all caregivers who received the delivered information from this system felt that the delivered information was useful. This result suggests that timely, precise and local information of outbreak situations might be a credible alternative for comparison with official nationwide information based on the Infection Control Law, but with a delay of longer than one week.

The volume and timing and frequency, once a week in the morning, were generally appropriate. However, results show that more than $20 \%$ of caregivers wanted to receive more information. Regarding contents, caregivers have much more interest in outbreak situations than in precautionary measures. This finding is expected to be beneficial for guiding later trials.

More than $80 \%$ of caregivers reported the delivered information to families or friends. This result suggests that the delivered information might penetrate gradually into the community through their communication even if they do not receive information directly from us. That penetration might support corporate childcare in the caregiver's workplace. If reliable information were more widely available, caregivers might arrange absence from the workplace more readily in cases of sudden onset in children. Thereby, caregivers can nurse an ill child and visit a doctor earlier. Finally, it might engender reduction of ill children at facilities and mitigate outbreaks in the community.

Overall, the benefits of this examination for families with children, which is the objective of the present study, were confirmed. Confirmation of the obtained results is robust throughout Japan should be necessary. NSASSy has been activated in $70 \%$ of all schools and $40 \%$ of all nursery schools in Japan [3]; PS has been operated nationwide. Therefore, the same framework was capable of being extended to other areas in Japan to check for robustness of the obtained results. That extension is left as a topic for future research. 
Another potential limitation was low participation rate, about 6\%, joining this trial among the members of the Child Care Support Service in ward A. However this low rate might not reflect low interest in the information of infectious diseases. Quite many users of the Child Care Support Service probably were caregivers of grown-up children at present and had not used the service recently, even though they used it formerly. They were non-active member. For the current study those non-active members should be deleted from a list of recipients of a recruit mail to join this trial. If the list were limited to active members of the Child Care Support Service, then the participation rate would rise considerably. However, the proportion of active members was not known. As described earlier, collaboration with the Child Care Support Service is expected to be the best way to recruit family with child care. Therefore, collaboration with them will continue when next trial will be performed in other areas. Fortunately, the Child Care Support Services exist in nationwide as described above. Several trials in other areas will evaluate the low participation rate in ward A comparison with other areas.

Moreover, to compensate a low participation rate if almost equal participation rates are achieved in other areas, the information will be provided through a home page as well as e-mail, as in the present study. The questionnaire after information delivery also will be set on the same home page. Through these approaches, non-member of the Child Care Support Service might joint this trial. However, the participants might then be biased toward inclusion of internet heavy users.

Finally, we have to mention about selection bias. As described above, we recruited participants from users and providers of the Child Care Support. Primarily, they might have a concern about children's health. Such tendency might cause the obtained result. Therefore, we cannot advocate that the obtained result was extended to be in general population of child bearing families. We showed only that the obtained result was held only in out used sample. So as to obtain the more robust result which might not be biased, we need to recruit participants other than from the Child Care Support. It remains as the next challenge.

\section{Conclusion}

Benefits of this examination for families with children were confirmed in a ward of Tokyo in winter. Extension of this examination nationwide in scope and year-round in duration is anticipated as the next challenge for development. After confirmation of its usefulness, we might recommend to introduce this system in all municipalities in Japan.

\section{Acknowledgements}

This study received funds from the SHISEIKAI Scholarship Fund for basic researchers of medical science: the Keiko Watanabe Award. We acknowledge the Child Integration Center, Department of Child-rearing Families, Shinjuku ward, 
Tokyo and Shinjuku Social Welfare Council for their support of this research.

\section{Conflicts of Interest}

No author has any conflict of interest, financial or otherwise, to declare in relation to this study.

\section{References}

[1] Nohara, M. and Kato, I. (2011) Child Raising Support for Working Parents: A Follow-up Study at a Daycare Facility. Journal of Tokyo Women's Medical University, 81, 408-415. (In Japanese)

[2] Kurita, J., Nagasu, N., Nagata, N., Okuno, H., Sugawara, T. and Ohkusa, Y. (2018) Outbreak of Human Metapneumovirus in Ibaraki, Japan and Its Descriptive Epidemiology. Health, 10, 749-757. https://doi.org/10.4236/health.2018.106057

[3] Kurita, J., Sugawara, T., Matsumoto, K., Nakamura, Y. and Ohkusa, Y. (2018) Association among (Nursery) School Absenteeism Surveillance System and Incidence of Infectious Diseases. School Health, 14, 21-27.

[4] Kurita, J., Nagasu, N., Nagata, N., Sakurai, N., Ohkusa, Y. and Sugawara, T. (2018) Articles Descriptive Epidemiology for Mycoplasma pneumoniae Infection Using (Nursery) School Absenteeism Surveillance System, and Proposal for Countermeasures. Journal of Biosciences and Medicines, 6, 33-42. https://doi.org/10.4236/jbm.2018.610005

[5] Shimatani, N., Sugishita, Y., Sugawara, T., Nakamura, Y., Ohkusa, Y., Yamagishi, T., et al. (2015) Enhanced Surveillance for the Sports Festival in Tokyo 2013: Preparation for the Tokyo 2020 Olympic and Paralympic Games. Japanese Journal of Infectious Diseases, 68, 288-295. https://doi.org/10.7883/yoken.JJID.2014.233

[6] Suzue, T., Hoshikawa, Y., Nishihara, S., Fujikawa, A., Miyatake, N., Sakano, N., et al. (2012) The New School Absentees Reporting System for Pandemic Influenza A/H1N1 2009 Infection in Japan. PLoS ONE, 7, e30639. https://doi.org/10.1371/journal.pone.0030639

[7] Nohara, M., Kurita, J., Sugawara, T. and Ohkusa, Y. (2018) Does Family with Children Need Information of Infectious Disease? Journal of Biosciences and Medicines, 6, 53-63. https://doi.org/10.4236/jbm.2018.612005

[8] Ministry of Health, Labour and Welfare (2018) About Community Child Rearing Support project (Child Care Support Service). http://www.mhlw.go.jp/bunya/koyoukintou/ikuji-kaigo01/ (in Japanese)

[9] Shinjuku City (2018) Class Closures Due to Inlfluenza-Like-Illness in Public Schools and Kindergarten Found by Shinjuku City, Tokyo. http://www.city.shinjuku.lg.jp/kodomo/gakko02_001014.html (in Japanese)

[10] Sugawara, T., Ohkusa, Y., Kawanohara, H. and Kamei, M. (2018) Short Term Prediction of Infectious Diseases Patients from Prescription Surveillance. Journal of Biosciences and Medicines, 6, 61-68. https://doi.org/10.4236/jbm.2018.69007

[11] Sugiura, H., Fujimoto, T., Sugawara, T., Hanaoka, N., Konagaya, M., Kikuchi, K., et al. (2013) Prescription Surveillance and Polymerase Chain Reaction Testing to Identify Pathogens during Outbreaks of Infection. BioMed Research International, 2013, Article ID: 746053. https://doi.org/10.1155/2013/746053

[12] Sugawara, T., Ohkusa, Y., Ibuka, Y., Kawanohara, H., Taniguchi, K. and Okabe, N. (2012) Real-Time Prescription Surveillance and Its Application to Monitoring Sea- 
sonal Influenza Activity in Japan. Journal of Medical Internet Research, 14, e14. https://doi.org/10.2196/jmir.1881

[13] Ohta, A., Murakami, Y., Hashimoto, S., Nagai, M., Kawado, M., Izumida, M., et al. (2007) Epidemics of Influenza and Pediatric Diseases Observed in Infectious Disease Surveillance in Japan, 1999-2005. Journal of Epidemiology, 17, S14-S22. https://doi.org/10.2188/jea.17.S14

[14] Yamakawa, M., Yamauchi, M., Nidaira, M., Azuma, T., Nakasone, T., Ando, F., Hayamizu, T., Kinjo, S. and Nakamura, Y. (2017) Enhanced Public Health Surveillance for the Sixth Worldwide Uchinanchu Festival Conducted by the Okinawa Prefectural Government. Japan Journal of Biosciences and Medicines, 5, 106-115. https://doi.org/10.4236/jbm.2017.59010

[15] Kambe, C., Fujii, H., Niu, T., Matsuura, H., Nagai, N., Nakamura, Y. and Nojiri, T. (2018) Enhanced Surveillance for National (Handicapped) Sports Games in Wakayama, Japan 2015. Journal of Biosciences and Medicines, 6, 35-47. https://doi.org/10.4236/jbm.2018.67004

[16] Ohkusa, Y., Sugawara, T., Kawanohara, H. and Kamei, M. (2018) Evaluation of the Global Action Plan on Antimicrobial Resistance in Japan during Its First Eighteen Months. Drug Discoveries \& Therapeutics, 12, 182-184.

https://doi.org/10.5582/ddt.2018.01011

[17] Sugawara, T., Ohkusa, Y., Kawanohara, H. and Kamei, M. (2018) Prescription Surveillance for Early Detection System of Emerging and Reemerging Infectious Disease Outbreaks. BioScience Trends, 12, 523-525. https://doi.org/10.5582/bst.2018.01201

[18] Siddiqui, M.R., Gay, N., Edmunds, W.J. and Ramsay, M. (2011) Economic Evaluation of Infant and Adolescent Hepatitis B Vaccination in the UK. Vaccine, 29, 466-475. https://doi.org/10.1016/j.vaccine.2010.10.075

[19] Zhou, F., Ortega-Sanchez, I.R., Guris, D., Shefer, A., Lieu, T. and Seward, J.F. (2008) An Economic Analysis of the Universal Varicella Vaccination Program in the United States. The Journal of Infectious Diseases, 197, S156-S164.

https://doi.org/10.1086/522135 